\section{A EVOLUÇÃO DO DIAGNÓSTICO DA DOENÇA MISTA DO TECIDO CONJUNTIVO}

\section{EVOLUTION OF THE DIAGNOSIS OF MIXED CONNECTIVE TISSUE DISEASE}

\author{
Alana Bazán Corrêa ${ }^{1}$, Marianne Schrader de Oiveira ${ }^{2}$, \\ Alessandra Peres ${ }^{3}$
}

\section{RESUMO}

A Doença Mista do Tecido Conjuntivo (DMTC) é uma doença autoimune crônica composta por um misto de quatro doenças: Lúpus Eritematoso Sistêmico, Esclerose Sistêmica, Dermatomiosite/Polimiosite e Artrite Reumatoide. Por se tratar de uma combinação de doenças autoimunes o diagnóstico é bastante complexo. Atualmente existem quatro combinações sugeridas por diferentes autores para a realização de um diagnóstico preciso, são eles: Kasukawa, Alarcón-Segovia e Villareal, Kahn e Appeboom e Sharp. Desde a sua descoberta em 1972 por Sharp, passaram-se 46 anos e desta forma o objetivo desta revisão foi verificar a evolução do diagnóstico da DMTC desde a sua descoberta até a atualidade. Para isso utilizou-se sites de busca PUBMED e SCIELO. Por se tratar de uma doença autoimune que leva ao desenvolvimento de um quadro inflamatório crônico utilizou-se a ferramenta STRING que permite a análise da interação de proteínas. Até a presente data, não existe um consenso de qual critério deve ser usado para o diagnóstico correto e eficiente desta doença. A baixa relação de interações observadas a partir da ferramenta STRING demonstra que ainda não existem dados suficientes na literatura para que a ligação entre proteínas marcadoras e a DTMC possa ser estabelecida.

Palavras-chave: Doença mista do tecido conjuntivo; revisão; bioinformática

\section{ABSTRACT}

Mixed connective tissue disease (MCTD) is a chronic autoimmune disorder consisting of a mixture of four diseases: systemic lupus erythematosus, systemic sclerosis, dermatomyositis/polymyositis, and rheumatoid arthritis. Because it is a combination of different autoimmune disorders its diagnosis is quite complex. Currently there are four combinations suggested by the following authors to establish an accurate diagnosis: Kasukawa, Alarcón-Segovia \& Villareal, Kahn, and Appeboom \& Sharp. It has been 46 years since Sharp reported the disease in 1972 and thus the purpose of this review was to investigate the evolution of the diagnosis of MCTD since then. PubMed and SciELO databases were used for this investigation. Because MCTD is an autoimmune disease that leads to the development of a chronic inflammatory condition, the STRING tool was used to allow the analysis of protein interaction. To date, there is no consensus as to what criterion should be used for a correct and efficient diagnosis of this disease. The low ratio of interactions observed from the STRING tool demonstrates that there is not yet enough data in the literature for establishing the binding between marker proteins and MCTD.

Keywords: Mixed connective tissue disease; review; bioinformatics

A Doença Mista do Tecido Conjuntivo (DMTC) é uma doença crônica autoimune sistêmica de recaídas e remissões. Teve seu conceito introduzido por Gordon Sharp em 1972, separando assim do conceito de apenas Doença do Tecido Conjuntivo (DTC) que havia persistido por décadas ${ }^{1}$. É composta por um misto de quatro doenças que podem ou não atacar o indivíduo de forma concomitante, são elas: Lúpus Eritematoso Sistémico (LES), Esclerose
Clin Biomed Res. 2019;39(1):89-96

1 Curso de Biomedicina, Centro Universitário Metodista (IPA). Porto Alegre, RS, Brasil.

2 Laboratório de Autoimunidade, Hospital de Clínicas de Porto Alegre. Porto Alegre, RS, Brasil.

3 Laboratório de Imunologia Celular e Molecular, Departamento de Ciencias Básicas da Saúde, Universidade Federal de Ciências Médicas de Porto Alegre. Porto Alegre, RS, Brasil

Autor correspondente: Alana Bazán Corrêa alanabazancorrea@gmail.com Hospital de Clínicas de Porto Alegre Rua Ramiro Barcelos, 2350 90035-903, Porto Alegre, RS, Brasil. 
Sistêmica (ES), Dermatomiosite/Polimiosite (DM/PM) e Artrite Reumatoide (AR) ${ }^{1}$.

O estudo de Sharp descreveu os achados clínicos e sorológicos de 25 pacientes, observados durante oito anos, como achados de uma síndrome de doença reumatológica distinta que chamou de DMTC. Neste mesmo estudo, foi detectado que a doença era estabilizada através de terapia com corticoides apresentando um melhor prognóstico ${ }^{1}$.

A doença ocorre mais frequentemente em indivíduos do sexo feminino e habitualmente nas segunda e terceira décadas de vida. Até o momento a DMTC tem sua etiologia desconhecida e não existem informações ou protocolos de orientação para avaliar se o indivíduo pode apresentar ou não a doença, sendo assim, não há consenso mundial sobre como, quando e em quem a doença pode ser diagnosticada bem como possíveis métodos de prevenção².

Uma correta classificação das doenças reumáticas é um desafio por se tratar de doenças multiformes e que frequentemente observa-se uma sobreposição clínica e laboratorial de suas manifestações ${ }^{2}$. Este problema é intensificado pela dificuldade de classificação e diagnóstico diferencial da DMTC, que ainda não possui um consenso de como ser corretamente diagnosticada ${ }^{3}$. Desde sua primeira descrição em 1972, permanece um intenso debate a respeito da forma como definir a doença se deve ser referida como uma doença distinta ou uma síndrome de sobreposição ${ }^{3}$. Enquanto não se chega a uma conformidade sobre a nomenclatura, continua-se usando o termo Doença Mista do Tecido Conjuntivo.

O objetivo desta revisão foi avaliar a evolução do diagnóstico da DMTC desde a sua descoberta por Sharp em 1972 até a atualidade. Assim como verificar associações de proteínas disponíveis na literatura através da ferramenta STRING como possível auxílio para um consenso no diagnóstico da DMTC bem como para estudos futuros.

\section{METODOLOGIA}

Para este estudo foram utilizados sites de busca PUBMED e SCIELO, por meio da palavra-chave: Doença Mista do Tecido Conjuntivo e seu respectivo termo em inglês, Mixed connective tissue disease, em que foram encontrados mais de dois mil e quinhentos artigos. Após, passar pelo filtro humans e diagnosis resultou em cerca de mil e quinhentos estudos. A seleção se deu por meio da leitura dos resumos. Não houve limitação do período de tempo e os trabalhos aceitos para este artigo encontram-se nos idiomas inglês, português e espanhol. A forma de organização da busca esta demonstrada abaixo na Figura 1.

Foram excluídos artigos que abordavam: estudo de caso; DMTC em crianças; não relatavam meios de diagnóstico; não estavam nos idiomas português, inglês ou espanhol; associação de outras doenças, como pulmonar e do Sistema Nervoso Central, ou síndromes em pessoas com DMTC; não possuíam o resumo submetido aos sites de busca; e, artigos que não continha em seu título o nome da doença de interesse. Os artigos foram analisados e incluídos nesta revisão até a primeira quinzena do mês de setembro do ano de dois mil e dezessete.

Foi utilizado o banco de dados STRING, rede funcional de associação de proteínas, onde foi testada a teoria de Ciang et al. ${ }^{4}$ de relação de proteínas específicas para um possível auxílio no diagnóstico da DMTC, juntamente com as proteínas citadas nos artigos que foram incluídos nesta revisão. São elas: CSK, IL-2, Fc IgG, Fc IgM, IL-10, TNF, U1A, U1C, SnRNP70, proteína C reativa, IL-6, IL-21, IL-16, LCK, e o CD40.

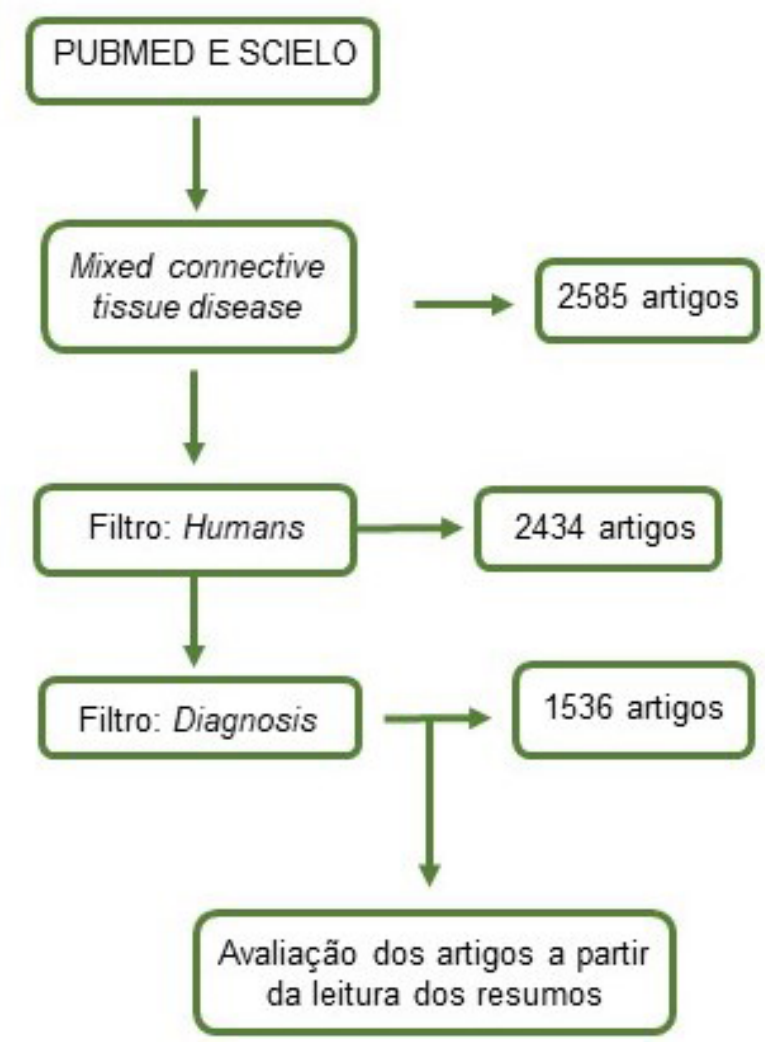

Figura 1: Diagrama de seleção dos artigos. 


\section{RESULTADOS}

A fim de elucidar a evolução do diagnóstico da DMTC criou-se uma linha do tempo. Acima da linha encontram-se os autores e os anos que marcam cada nova descoberta e suas alternativas de diagnóstico, abaixo dessa linha estão os critérios utilizados para cada diagnóstico, bem como os sinais clínicos e sorológicos (Figura 2).
Após a leitura dos artigos que foram incluídos nesta revisão organizou-se uma lista de proteínas citadas nos artigos relacionadas a DMTC. Para a análise utilizou-se a ferramenta de bioinformática denominada STRING. Através do banco de dados desse instrumento foi observada a associação demonstrada na Figura 3. Com o intuito de facilitar a compreensão organizou-se a seguir, na Tabela 1 ,

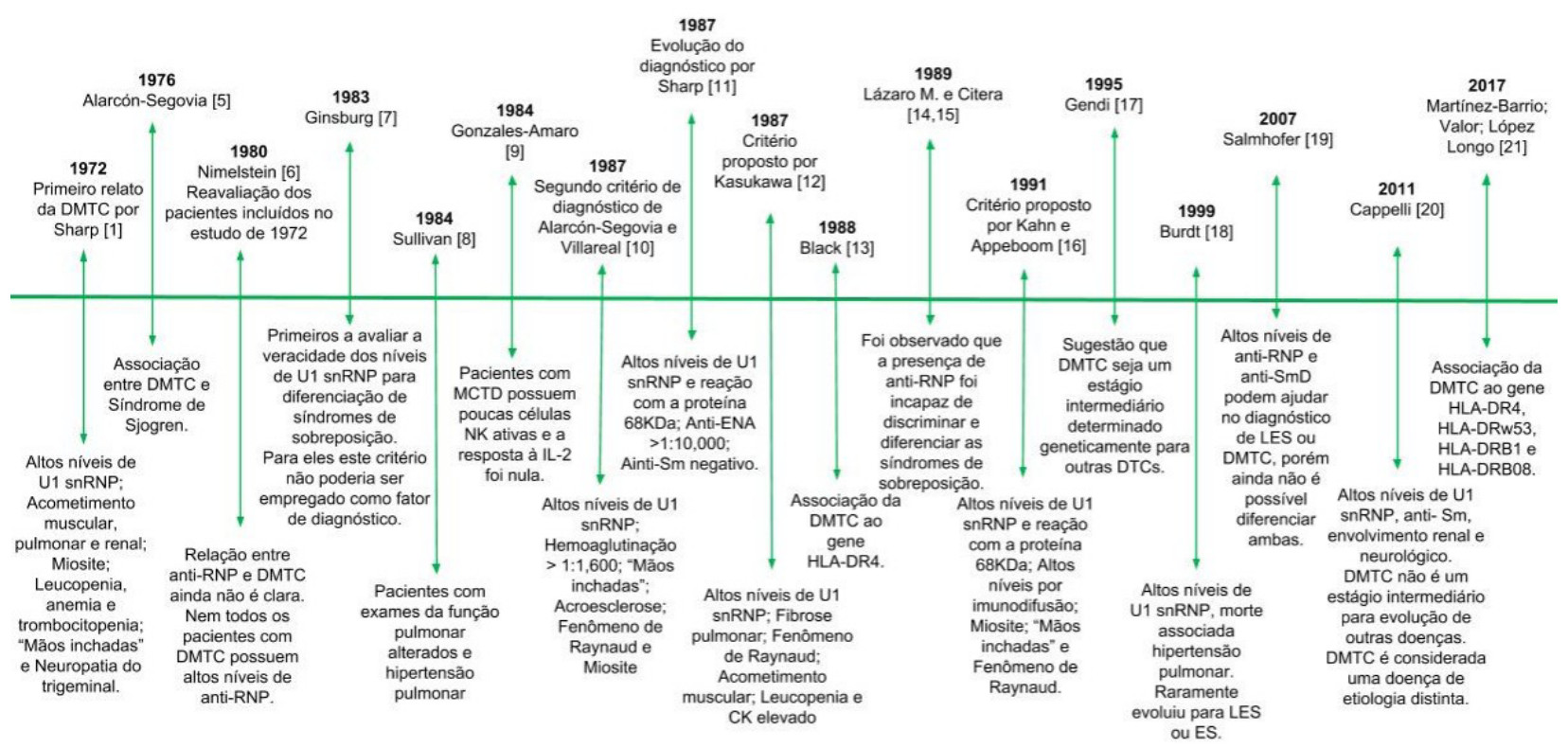

Figura 2: Linha do tempo elucidando a evolução do diagnóstico da DMTC.

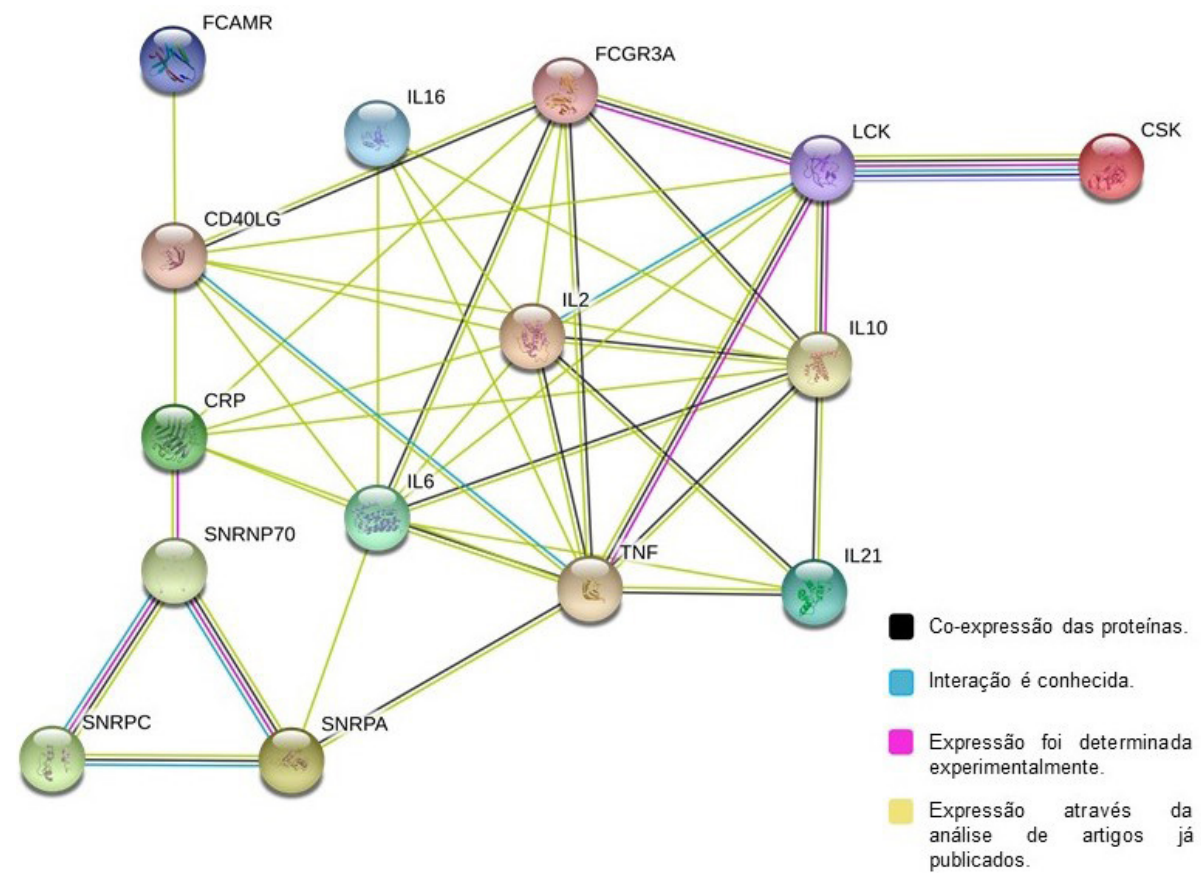

Figura 3: Resultado da teoria de associação das proteínas realizado no banco de dados STRING, rede funcional de associação de proteínas, para o possível diagnóstico mais específico de DMTC com um $\mathrm{p}<0.01$. 
Tabela 1: Lista de proteínas e suas descrições associadas na ferramenta STRING.

\begin{tabular}{|c|c|}
\hline PROTEÍNAS & DESCRIÇÃO \\
\hline CSK & $\begin{array}{l}\text { Proteína Tirosina Quinase não receptora que desempenha um papel importante na regulação do } \\
\text { crescimento celular }^{5}\end{array}$ \\
\hline IL2 & Interleucina 2. Produzido por células T em resposta a estimulação antigênica ou mitogênica ${ }^{6}$ \\
\hline SNRPA & Polipeptídio A da ribonucleoproteína nuclear. Componente do snRNP U12 \\
\hline SNRPC & Polipeptídio C da ribonucleoproteína nuclear; Componente do snRNP U1² \\
\hline CRP & Proteína C reativa ${ }^{4}$ \\
\hline IL6 & Interleucina 6 . Citocina com uma grande variedade de funções biológicas ${ }^{6,7}$ \\
\hline IL21 & Interleucina 21. Citocina com atividade imunorreguladora ${ }^{7}$ \\
\hline IL16 & Interleucina 16. Estimula uma resposta migratória em linfócitos CD4+4 \\
\hline FCAMR & Receptor Fc IgM4,8 \\
\hline LCK & Proteína tirosina quinase específica para linfócitos ${ }^{9}$ \\
\hline FCGR3A & Receptor $\mathrm{Fc}_{\mathrm{C} \lg \mathrm{G}^{8}}$ \\
\hline CD40LG & Estimula a proliferação de células $T$ e a produção de citocinas ${ }^{4}$ \\
\hline TNF & Fator de necrose tumoral 6,7 \\
\hline IL10 & Interleucina 10. Inibe a síntese de várias citocinas ${ }^{10}$ \\
\hline SNRNP70 & Ribonucleoproteína nuclear 70kDa (U1). Componente do snRNP U11 \\
\hline
\end{tabular}

uma lista completa das proteínas pesquisadas nessa associação, bem como a descrição de cada uma.

Através da utilização de linhas com cores distintas esta ferramenta permite identificar os diferentes tipos de relações das proteínas selecionadas. Dentre as proteínas selecionadas pode-se observar através da coloração preta que existe uma co-expressão das proteínas quando a proteína de interesse, SNRNP70, está sendo expressa. A linha amarela representa a expressão observada através da análise de artigos já publicados (textmining), a linha azul indica que a interação é conhecida e já foi visualizada em outros bancos de dados e a linha rosa representa que a expressão foi determinada experimentalmente. Observa-se também que a SNRNP70 possui outras interações previstas que não foram contempladas como: genes vizinhos, fusões de genes e a co-ocorrência de genes.

Ainda, com relação a Figura 3 os nós de rede simbolizam proteínas, ou seja, cada nó representa todas as proteínas produzidas por um único locus do gene que codifica a proteína. Nódulos coloridos: consulta de proteínas e primeiro nível de interação. Nós brancos: segundo nível de interação. Nós vazios: proteínas cuja estrutura em 3D é desconhecida. Nós preenchidos: parte da estrutura em 3D é conhecida ou prevista.

Quanto à análise estatística obtivemos um valor de $p<0.01$, este resultado se refere a interação proteína-proteína apresentada pelo programa. Este valor obtido demonstra que as interações propostas previamente são significativas, pois o programa STRING usa $p<0.05$ para significância.

Foram testadas também outras associações de proteínas como: U1A, U1C, U2, Síndrome de Sjögren antígeno B (SSB), SnRNP 40KDa, SnRNP 68KDa, U4, U5, SnRNP 70KDa, CD4, CD8, CD16 e proteínas pré-mRNA, porém não obtivemos uma associação e uma significância considerável das mesmas.

\section{DISCUSSÃO}

ADMTC foi descoberta em 1972 por Sharp et al. ${ }^{1}$. Para o diagnóstico sorológico a dosagem dos níveis do anticorpo dirigido contra a ribonucleoproteína nuclear U1 snRNP indica uma condição provável de DMTC ${ }^{1}$. Esses anticorpos foram detectados originalmente por imunodifusão, descritos pela primeira vez em soro de pacientes com Lúpus Eritematoso Sistêmico (LES) e ganharam atenção com o novo conceito descrito por Sharp diferenciando DMTC de DTC ${ }^{2}$. Porém nem todos os pacientes possuem este anticorpo em altos níveis. Atualmente existem quatro alternativas sugeridas por diferentes autores para a realização de um diagnóstico mais preciso: Alarcon-Segovia e Villarreal ${ }^{10}$, Kasukawa et al. ${ }^{12}$, Kahn e Appelboom ${ }^{16}$ e Sharp et al. ${ }^{1}$, sendo este último o primeiro critério de diagnóstico realizado. Estes novos critérios foram desenvolvidos levando em consideração sinais clínicos e sorológicos, uma vez que o critério de Sharp não contemplava todos os pacientes acometidos com DMTC 4 .

O critério de Alarcón-Segovia e Villareal, onde os autores sugeriram que fosse avaliado, além dos altos níveis de U1 snRNP, outras características clínicas como a hemoaglutinação, "mãos inchadas", acroesclerose, fenômeno de Raynaud e miosite ${ }^{11}$, apresentou maior sensibilidade e especificidade comparado ao critério de Sharp. O critério de Kasukawa que propôs a avaliação de características 
clínicas e sorológicas como a fibrose pulmonar e a proteína Tirosina Quinase $(C K)^{12}$, é mais sensível em comparação com o de Alarcón-Segovia e Sharp ${ }^{4}$.

Porém em um estudo realizado na Noruega não encontrou diferença estatística entre os critérios de Sharp, Alarcón-Segovia e Kasukawa. Este mesmo estudo indicou que os critérios podem ser equivalentes uma vez que os mesmos possuem muitas similaridades tais como os altos níveis de U1 snRNP, fenômeno de Raynaud e miosite ${ }^{2}$.

Segundo Sharp et al. ${ }^{1}$ e Gunnarsson et al. ${ }^{2}$, a DMTC apresenta um bom prognóstico, assim como outras doenças autoimunes, porém o mesmo varia entre os pacientes portadores da doença. Ambos autores relatam que a doença deve ser tratada através de terapia com corticoides e imunossupressores para que a doença se estabilize. Os pacientes não podem parar com este tratamento, uma vez iniciado, ele persiste durante toda a vida, mesmo nos períodos de remissão e nos períodos de atividade da DMTC.

O principal marcador considerado até o momento é a presença de altos níveis de anticorpos dirigidos contra a ribonucleoproteína nuclear U1 snRNP associado a avaliação clínica, acometimento muscular, "mãos inchadas", leucopenia, miosite e envolvimento neurológico ${ }^{1}$. Porém, não são todos os pacientes que expressam este anticorpo ou sintomas clássicos da doença ${ }^{14}$. O anti-U1-RNP foi detectado de 75 a 90\% dos pacientes com DMTC. Foi detectado também em 20 a $50 \%$ dos pacientes diagnosticados com LES ${ }^{4}$.

A doença possui uma fase de atividade e também uma fase de remissão. Em ambas situações, pode-se observar e associar os níveis de anticorpos anti-RNP. A remissão foi associada ao desaparecimento ou aos baixos níveis de anti-RNP, fazendo com que esse anticorpo não pudesse ser detectado em sangue periférico ${ }^{22}$. A fase de atividade da doença foi associada aos altos níveis de anti-RNP. Os anticorpos anti-RNP ligam três proteínas específicas: A, C e 70kDA do complexo macromolecular U1 snRNP. Estudos realizados indicam que o antígeno $70 \mathrm{KDa}$ é o principal alvo dos anticorpos anti-RNP na DMTC ${ }^{2}$, porém os investigadores não descartaram a possibilidade de que as outras proteínas pertencentes a este complexo também possam ser alvo de anti-RNP. Usando a ferramenta STRING, foi possível visualizar que quando a proteína 70KDa está sendo expressa, ocorre uma co-expressão das outras proteínas do complexo U1 snRNP, as proteínas U1A e U1C.

Com relação ao perfil de anticorpos produzidos, o anticorpo IgM foi significativamente observado em pacientes com LES. Já o anticorpo lgG foi secretado de forma mais abundante em LES do que na DMTC, e a reatividade foi semelhante para ambas doenças. A partir da combinação da lgM com o anticorpo
anti-U1C, observou-se que foi possível a realização da diferenciação de pacientes que possuíam DMTC dos que possuíam LES, com uma precisão de $71,3 \%{ }^{4,23}$. Pacientes com DMTC são menos propensos do que pacientes com LES a reter anticorpos IgM U1, e o elevado nível de IgG específica para U1 é típico para DMTC, transmitindo alta especificidade ${ }^{23}$.

Swanton e Isenberg ${ }^{22}$ relatou que os níveis de IgG foram observados em pacientes cuja doença estava na fase inicial ou ainda não havia entrado em fase de remissão. Porém a presença de lgG na fase inicial da doença foi significativamente maior nos pacientes que vieram a óbito do que os pacientes que entraram na fase de remissão.

A realização de um diagnóstico adequado se tornou difícil nos dias atuais, pois até o momento não há um consenso entre pesquisadores e médicos. Por se tratar de uma doença onde os parâmetros não são compartilhados entre os pacientes, a avaliação de cada paciente é realizada de forma isolada, em que cada sintoma é analisado separadamente. É utilizado até o momento para diagnóstico os parâmetros descritos pelos quatro principais autores que fizeram avanços em relação a DMTC: Sharp et al. ${ }^{1}$; Alarcón-Segovia e Villareal ${ }^{10}$, Kasukawa et al. ${ }^{12}$ e Kahn e Appeboom ${ }^{16}$.

Conforme observado na linha do tempo, Alarcón-Segovia e Villareal ${ }^{10}$, além de realizarem a associação da DMTC com a Síndrome de Sjorgen, descoberta em 1976, conseguiram em 1987 associar a doença com o parâmetro de hemoaglutinação. No mesmo ano o Fenômeno de Raynaud, utilizado atualmente como mais um marcador da doença, teve seu conceito introduzido por estes autores juntamente com a Acroesclerose.

O desafio do correto diagnóstico da doença é encontrar um parâmetro específico para DMTC, seja sorológico ou de avaliação clínica. Os estudos demonstram a dificuldade em estabelecer como critério de diagnóstico os altos níveis de anticorpos dirigidos contra a ribonucleoproteína nuclear U1 snRNP. Esta resistência é justificada devido à presença deste mesmo anticorpo em várias doenças autoimunes, principalmente em LES, onde os indivíduos acometidos expressam um alto nível de anti-RNP assim como os pacientes com DMTC ${ }^{19}$.

$\mathrm{Na}$ avaliação do perfil celular dos indivíduos foi possível verificar que os pacientes com DMTC apresentam uma menor frequência de células CD4 quando comparados a indivíduos saudáveis. A cada episódio da doença, essa frequência sofre redução ${ }^{4}$. Em outro estudo avaliando a presença de células CD4+CD25+ foi observada uma menor frequência de células com este fenótipo, e quando a doença estava em atividade esse número caía ainda mais. Esta redução foi acompanhada de um 
aumento nas secreções de IL-10 quando a doença estava no período de atividade ${ }^{24}$. Neste mesmo estudo houve também a identificação de altos níveis séricos de IL-6. Essa elevação pode representar um desempenho importante para o desenvolvimento de células T reguladoras. A ligação da IL-6 à membrana do receptor de IL-6 (mbIL-6R), pode ser capaz de suprimir a proliferação de células T CD4+CD25+o que explicaria a redução da sua frequência. Além disso, o TGFb, outra citocina que afeta a resposta imune, foi encontrado inibindo a secreção de IL-2 e por consequência a proliferação de células $T$. Estudos recentes sugeriram que as citocinas derivadas de células $T$ possam ter um papel importante na expansão das células produtoras de autoanticorpos e na determinação da especificidade de anticorpos como o anti-RNP25.

As células $B$ podem agir como células apresentadoras de antígeno (APCs), o que permite o processamento e apresentação de antígenos, bem como liberar sinais co-estimulatórios para as células $T$. Células $B$ podem também secretar citocinas pró-inflamatórias como interferon gama, IL-6 e TNF alfa, podendo causar dano ao tecido e atrair assim outras células inflamatórias ${ }^{25}$.

Recentemente, a IL-21 tem sido relacionada a patogênese das doenças autoimunes. Pesquisas mostraram que esta interleucina desempenha um papel como moduladora da resposta autoimune adaptativa em pacientes com doenças como AR e LES ${ }^{26}$. Em pacientes com AR, foi observado um aumento nos níveis de IL-6 e TNF, podendo ser interpretado como um indicador de inflamação. Porém, não foi encontrada uma relação das mesmas com os processos patológicos da doença e parâmetros clínicos e sorológicos ${ }^{27}$.

Para a realização de um diagnóstico diferencial, Wiemann et al. ${ }^{28}$, pesquisaram os níveis de autoanticorpos dirigidos contra a Caseína Quinase II (CKII). Os pesquisadores buscaram verificar os níveis deste anticorpo nos pacientes acometidos pela DMTC e quais as subunidades que estão relacionadas com o anti-RNP70. Para isso realizaram uma comparação do teste de CK indireta e ELISA CKII, porém o teste para CK indireta não forneceu informações sobre a localização dos principais epítopos imunogênicos da CKII. Em 15\% dos pacientes positivos para anti-RNP70 investigados, foi possível observar uma positividade para anti-CKII. O teste ELISA CKII apresentado pelos autores mostrou-se eficiente para a realização de um diagnóstico diferencial para DMTC. Todavia, não foi possível encontrar uma correlação entre a ocorrência do anticorpo anti-CKII e o anticorpo anti-RNP7028.

A proteína Tirosina Quinase (CSK) desempenha um papel importante na resposta imune. Resíduos de fosforilização de tirosina estão localizados na proteína Tirosina Quinase específica para Linfócitos, p56 (LCK) resultando em uma interação que resulta na inibição de uma destas duas proteínas ${ }^{29}$. Foi observado que as proteínas CSK e LCK podem estar ligadas, devido a relação entre estas proteínas. Já foi demonstrado que quando ocorre o aumento da atividade da LCK observa-se uma inibição da CSK de forma concomitante. Esta inibição pode ocorrer para uma melhor sinalização após a estimulação das células $T$.

De acordo com os dados encontrados na literatura os marcadores mais inovadores parecem estar relacionados as proteínas HLA que possuem papel fundamental na apresentação de antígenos próprios e indução da resposta autoimune ${ }^{13}$.

Um estudo avaliou 46 pacientes e propôs que a DMTC seria um estágio intermediário de evolução para outras DTC conhecidas e podendo ser geneticamente determinado ${ }^{17}$, uma vez que a mesma foi associada ao gene HLA-DR4 em pesquisas realizadas anteriormente ${ }^{13}$. Contudo, regiões do cromossomo 3 foram identificadas em estudos de associação e ligação de todo o genoma ${ }^{25}$. Estudos recentes evidenciaram uma forte relação da DMTC com os seguintes genes: HLA-DR4, HLA-DRw53, HLA-DRB1 e HLA-DRB08. Portanto a DMTC pode ser considerada geneticamente diferente de LES, já que está relacionada aos genes HLD-DR2 e HLA-DR3. Este genótipo afirma que a DMTC é uma doença distinta, com suas próprias características e não poderia ser considerada como um estágio intermediário de evolução para outras doenças ${ }^{21}$.

Além disso, Burdt ${ }^{18}$ e Cappelli ${ }^{20}$, mostraram que a DMTC é uma doença de etiologia distinta, portanto, não pode ser considerada como um estágio intermediário de evolução para outras doenças. Cappelli et al. ${ }^{20}$ fez uma comparação com três diferentes critérios de diagnóstico (Kasukawa ${ }^{12}$, Alarcón-Segovia ${ }^{10}$ e Sharp et al. ${ }^{1}$ ) em 161 pacientes. A maioria destes pacientes mantiveram as características clínicas e sorológicas de quando foram diagnosticados, o que para os pesquisadores, é possível concluir que a DMTC é uma doença e não um estágio intermediário para outra DTC.

Conforme o levantamento realizado para esta revisão foi observado que, desde o ano de 1991, não houveram mudanças na forma em que o diagnóstico é realizado, já que os estudos publicados após o de Kahn e Appelboom ${ }^{16}$, não mostraram resultados significativos para que houvesse alguma alteração no mesmo. Todavia, durante estes 46 anos, desde que a DMTC foi relatada como doença até os dias atuais, não obtivemos avanços significativos em relação ao diagnóstico. 
Embora já tenham se passado 46 anos após o primeiro relato da DTMC até a presente data, não existe um consenso de qual critério deve ser usado para o diagnóstico correto e eficiente desta doença. Essa não conformidade gera demora e dúvidas. Alguns pacientes ficam na espera de um diagnóstico por muito tempo, pois em algumas situações não é possível identificar se o indivíduo está realmente sendo acometido pela doença. A baixa relação de interações observadas a partir da ferramenta STRING demonstra que ainda não existem dados suficientes na literatura para que a ligação entre proteínas marcadoras e a DTMC possa ser estabelecida. Sendo assim, mais estudos são necessários para que um consenso entre marcadores biológicos e a clínica acelerem o processo de diagnóstico permitindo um tratamento mais rápido e eficaz.

\section{Conflitos de Interesse}

Os autores declaram não ter conflitos de interesse.

\section{REFERÊNCIAS}

1. Sharp GC, Irvin WS, Tan EM, Gould RG, Holman HR. Mixed connective tissue disease-an apparently distinct rheumatic disease syndrome associated with a specific antibody to an Extractable Nuclear Antigen (ENA). Am J Med. 1972;52(2):148-59. PMid:4621694.

2. Gunnarsson R, Hetlevik SO, Lilleby $\vee$, Molberg $\varnothing$. Mixed Connective Tissue Disease. Best Pract Res Clin Rheumatol. 2016;30(1):95-111. PMid:27421219.

3. Tani C, Carli L, Vagnani S, Talarico $\mathrm{R}$, Baldini C, Mosca M, et al. The diagnosis and classification of mixed connective tissue disease. J Autoimmun. 2014;48-49:46-9. PMid:24461387.

4. Ciang NC, Pereira N, Isenberg DA. Mixed connective tissue diseaseenigma variations? Rheumatology. 2017;56(3):326-33. PMid:27436003.

5. Alarcón-Segovia D. Symptomatic Sjögren's syndrome in mixed connective tissue disease. $J$ Rheumatol. 1976;3(2):191-5. PMid:950635.

6. Nimelstein SH, Brody S, McShane D, Holman HR. Mixed connective tissue disease: a subsequent evaluation of the original 25 patients. Medicine. 1980;59(4):239-48. PMid:6967141.

7. Ginsburg WW, Conn DL, Bunch TW, McDuffie FC. Comparison of clinical and serologic markers in systemic lupus erythematosus and overlap syndrome: a review of 247 patients. J Rheumatol. 1983;10(2):235-41. PMid:6864677.

8. Sullivan WD, Hurst DJ, Harmon CE, Esther JH, Agia GA, Maltby JD, et al. A prospective evaluation emphasizing pulmonary involvement in patients with mixed connective tissue disease. Medicine. 1984;63(2):92-107. PMid:6700436.

9. González-Amaro R, Alcocer-Varela J, Martínez-Cordero E, AlarcónSegovia D. Natural killer cell-mediated activity in mixed connective tissue disease and its response to induction by interleukin-2. J Clin Immunol. 1984;4(4):273-9. PMid:6611347.

10. Alarcón-Segovia D, Villarreal M. Classification and diagnostic criteria for mixed connective tissue disease. In: Kasukawa R, Sharp GC, editores. Mixed connective tissue disease and anti-nuclear antibodies. Amsterdam: Elsevier; 1987. p. 33-40.

11. Sharp GC. Diagnostic criteria for classification of MCTD. In: Kasukawa $\mathrm{R}$, Sharp GC, editores. Mixed connective tissue disease and anti-nuclear antibodies. Amsterdam: Elsevier; 1987; 1987. p. 23-30.

12. Kasukawa R, Tojo T, Miyawaki S, Yoshida H, Tanimoto K, Nobunaga $M$, et al. Preliminary diagnostic criteria for classification of mixed connective tissue disease. In: Kasukawa R, Sharp $\mathrm{GC}$, editores. Mixed connective tissue disease and anti-nuclear antibodies. Amsterdam: Elsevier; 1987. p. 41-7. (no. 3).

13. Black CM, Maddison PJ, Welsh KI, Bernstein R, Woodrow JC, Pereira RS. HLA and immunoglobulin allotypes in mixed connective tissue disease. Arthritis Rheum. 1988;31(1):131-4. PMid:3345219.

14. Lázaro MA, Maldonado Cocco JA, Catoggio LJ, Babini SM, Messina OD, García Morteo O. Clinical and serologic characteristics of patients with overlap syndrome: is mixed connective tissue disease a distinct clinical entity? Medicine. 1989;68(1):58-65. PMid:2642587.
15. Citera G, Lázaro MA, Maldonado Cocco JA. Mixed connective tissue disease: fact or fiction? Lupus. 1995;4(4):255-7. PMid:8528219.

16. Kahn MF, Appelboom T. Syndrome de Sharp. In: Kahn MF, Peltier AP, Mayer $\mathrm{O}$, Piette JC, editores. Les maladies systemiques. Paris: Flammarion; 1991. p. 545-56.

17. Gendi NS, Welsh KI, Van Venrooij WJ, Vancheeswaran R, Gilroy J, Black CM. HLA type as a predictor of mixed connective tissue disease differentiation: ten-year clinical and immunogenetic followup of 46 patients. Arthritis Rheum. 1995;38(2):259-66. PMid:7848317.

18. Burdt MA, Hoffman RW, Deutscher SL, Wang GS, Johnson JC, Sharp GC. Long-term outcome in mixed connective tissue disease: longitudinal clinical and serologic findings. Arthritis Rheum. 1999;42(5):899-909. PMid:10323445.

19. Salmhofer W, Hermann J, Joch M, Kerl H, Graninger W. High serum levels of antibodies against the recombinant $70 \mathrm{kDa}$ ribonucleoprotein are useful for diagnosing mixed connective tissue disease. J Eur Acad Dermatol Venereol. 2007;21(8):104753. PMid: 17714123.

20. Cappelli S, Bellando Randone S, Martinović D, Tamas MM, Pasalić $\mathrm{K}$, Allanore $\mathrm{Y}$, et al. "To be or not to be," ten years after: evidence for mixed connective tissue disease as a distinct entity. Semin Arthritis Rheum. 2012;41(4):589-98. PMid:21959290.

21. Martínez-Barrio J, Valor L, LópezLongo FJ. Hechos y controversias en la enfermedad mixta del tejido conectivo. Med Clin. 2018;150(1):2632. http://dx.doi.org/10.1016/j. medcli.2017.06.066. 
22. Swanton J, Isenberg D. Mixed connective tissue disease: still crazy after all these years. Rheum Dis Clin North Am. 2005;31(3):421-36, v. PMid:16084316.

23. Mesa A, Somarelli JA, Wu W, Martinez L, Blom MB, Greidinger $E L$, et al. Differential immunoglobulin class-mediated responses to components of the U1 small nuclear ribonucleoprotein particle in systemic lupus erythematosus and mixed connective tissue disease. Lupus. 2013;22(13):1371-81. PMid:24158973.

24. Baráth S, Sipka S, Aleksza M, Szegedi A, Szodoray P, Végh $\mathrm{J}$, et al. Regulatory $\mathrm{T}$ cells in peripheral blood of patients with mixed connective tissue disease. Scand J Rheumatol. 2006;35(4):3004. PMid:16882595.

25. Hoffman RW, Maldonado ME. Immune pathogenesis of Mixed Connective Tissue Disease: a short analytical review. Clin Immunol. 2008;128(1):817. PMid:18439877.

26. Kunz M, Ibrahim SM. Cytokines and cytokine profiles in human autoimmune diseases and animal models of autoimmunity. Mediators Inflamm. 2009;2009:979258.

PMid:19884985.
27. Burska A, Boissinot M, Ponchel F. Cytokines as biomarkers in rheumatoid arthritis. Mediators Inflamm. 2014;2014:545493. PMid:24733962.

28. Wiemann C, Bodenbach L, Pyerin W. Antibodies to casein kinase II in sera of patients with mixed connective tissue disease: evaluation with recombinant proteins. Clin Chem. 1993;39(12):2492-4. PMid:8252720.

29. Moogk D, Zhong S, Yu Z, Liadi I, Rittase W, Fang V, et al. Constitutive Lck activity drives sensitivity differences between CD8+ memory T cell subsets. J Immunol. 2016;197(2):644-54. PMid:27271569.

Recebido: 4 out, 2018 Aceito: 5 jan, 2019 